\title{
Rüzgâr Enerjisi Dönüşüm Sistemlerinde Maksimum Güç Noktası İzleme Kontrolünün Farklı Yöntemler Üzerinden Karşılaştırmalı Analizi
}

\author{
Hasan Bektaş PERÇİN ${ }^{*}$, Abuzer ÇALIŞKAN ${ }^{2}$ \\ ${ }^{1}$ Elektrik Elektronik Mühendisliği Bölümü, Mühendislik Fakültesi, Fırat Üniversitesi, Elâzı̆̆g, Türkiye \\ ${ }^{2}$ Elektrik Elektronik Mühendisliği Bölümü, Mühendislik Fakültesi, Fırat Üniversitesi, Elâzığg, Türkiye \\ ${ }^{* 1}$ hbpercin@ firat.edu.tr, ${ }^{2}$ acaliskan@ firat.edu.tr
}

Öz: Rüzgâr enerjisi, elektrik üretiminde kullanımı giderek artan bir enerji kaynağıdır. Son yıllarda rüzgâr enerjisi dönüşüm sistemlerinde değişken hızlı rüzgâr türbinleriyle uyumlu kalıcı mıknatıslı senkron generatörler ön plana çıkmaktadır. Bu tip generatörler elektriksel kayıpları azaltabileceği gibi mekanik bileşenlere bağımlılığı azaltarak genel sistem performansını yükseltir. Rüzgâr enerjisinde verimlilik, sadece verimli elemanların değil aynı zamanda uygun kontrollerin seçimine bağlıdır. Dönüşüm sistemlerinde anlık rüzgâra göre sistem verimliliğini en üst seviyede tutabilmek için maksimum güç noktası izleme kontrollerinden yararlanılır. Bu çalışmada; dönüşüm sistemin bileşenlerinin sistem büyüklükleri üzerinden çalışma prensipleri açıklanmış. Kanat uç hız oranı, tepe tırmanma ve bulanık mantık tabanlı maksimum güç noktası izleme kontrol yöntemleri açıklanmıștır. $\mathrm{Bu}$ kontrol yöntemleri, Matlab/Simulink ortamında modellenerek çeşitli sistem büyüklükleri üzerinden karşılaştırmalı analizleri gerçekleştirilmiştir.

Anahtar kelimeler: Rüzgâr Enerjisi, Kalıcı Mıknatısı Senkron Generatör, Matlab/Simulink, Maksimum Güç Noktası İzleme, Bulanık Mantık

\section{Comparative Analysis of Maximum Power Point Tracking Control Through Different Methods in Wind Energy Conversion Systems}

\begin{abstract}
Wind energy is a renewable energy source increasingly used in electricity generation. In recent years, permanent magnet synchronous generators compatible with variable speed wind turbines have come to the fore in wind energy conversion systems. This type of generator can reduce electrical losses and increase overall system performance by reducing dependency on mechanical components. The efficiency in wind energy depends on not only the selection of suitable components but also proper control techniques In conversion systems, maximum power point tracking controls are utilized to keep the system efficiency at the highest level according to the instant wind. In this study; the working principles of the conversion system components are expressed over the system parameters. Tip speed ratio, hill climbing and fuzzy logic-based maximum power point tracking control methods are explained. These control methods are modeled in Matlab / Simulink environment and comparative analyzes are carried out over various system parameters.
\end{abstract}

Key words: Wind Energy, Permanent Magnet Synchronous Generator, Matlab/Simulink, Maximum Power Point Tracking Control, Fuzzy Logic

\section{Giriş}

Yüzyıllar boyu çeşitli amaçlarla kullanılan rüzgâr enerjisi, geçtiğimiz yüzyılın ikinci yarısından itibaren ortaya çıkan türbin teknolojileriyle elektrik üretiminde de kullanılmaya başlanmıştır. Fosil yakıt tabanlı enerji üretiminde artan maliyetler, nükleer enerji ile ilgili çekinceler, çevresel ve küresel 1sınma üzerine artan kaygılar rüzgâr gibi yenilenebilir ve sürdürülebilir kaynaktan enerji üretimini arttırmıştır [1].

Rüzgârdan elektrik enerjisi elde etmek için kullanılan rüzgâr enerjisi dönüşüm sistemi (REDS)'ler, rüzgârdaki kinetik enerjiyi önce mekanik enerjiye daha sonra da elektrik enerjisine dönüştüren sistemlerdir. İlk zamanlarda REDS'lerde sabit hızlı türbinler kullanılmaktaydı. Ancak değişen rüzgâr koşullarına göre düşük verimlilikle çalışmaları, anlık rüzgâra göre hızı ayarlanabilen daha yüksek verimli, değişken hızlı türbinlerin kullanımını arttırmıştır. Enerji üretiminde kullanılan generatörler açısından bakıldığında ise son yıllarda dışardan uyartıma ihtiyaç duymadan çalışan güçlü mekanik karakteristiğe sahip kalıcı mıknatıslı senkron generatör (KMSG)'ler ön plana çıkmaktadır. Doğrudan türbin yapısıyla bağlanabilecek şekilde tasarlanabilmeleri, giderek düşen maliyetleri rüzgâr enerjisinde kullanımlarını yaygınlaştırmıştır [2-3].

\footnotetext{
* Sorumlu yazar: hbpercin@ firat.edu.tr. Yazarların ORCID Numarası: ${ }^{1}$ 0000-0001-8968-969X, ${ }^{2}$ 0000-0001-8262-7912
} 
REDS için kullanılan türbin ve generatör seçimi kadar kullanılan sistemin anlık değişen rüzgâr koşullarına göre kontrolü de önemlidir. REDS'lerde rüzgârdan anlık maksimum seviyede yararlanabilmek için maksimum güç noktası izleme (MGNI) kontrollerinden yararlanılır. Kontrol yönteminin temel çalışma prensibi, değişken hızlı kullanıma uygun REDS'lerde generatörün çalışma hızının belirli hız aralıklarında rüzgâr hızına göre ayarlanmasına dayanmaktadır. Kullanılan kontrol yapıları daha az maliyetli ve daha verimli enerji üretimine imkân verir [3].

Kullanılan kontrol teknikleri için REDS'de üretilen enerjinin şebekeye ya da şebekeden bağımsız yüke aktarımında kullanılan arayüzler ön plandadır. MGNİ yöntemleri için kullanılan kontrol yapıları kullanılan arayüz tipine göre farklılık gösterebilmektedir. Bu arayüz yapılarından kıyıcılı arayüzlerde kıyıcı devresindeki yarıiletken anahtarın doluluk oranı üzerinden değişken rüzgâr hızlarında MGNİ kontrolü gerçekleştirilebilmektedir [4].

Literatürde kıyıcılı arayüz yapısını kullanan REDS’lerde farklı şekillerde MGNİ kontrolünü gerçekleştiren çalışmalar mevcuttur. Kontrol uygulamalarında sıklıkla kullanılan PID tabanlı MGNİ uygulamalarında [5- 6] farklı sistem parametrelerinin referans değerlerine göre hata değeri üzerinden çalışma sağlanmıştır. Özellikle lineer özelikteki sistemler için iyi performans veren bu kontrol yapıları REDS gibi hızlı rüzgâr değişimlerine maruz kalan sistemlerde düşük performans gösterebilir. MGNİ kontrolü için kullanılan diğer bir yaklaşımda ise güneş enerjisi sistemlerinde de kullanılan seçilen kontrol değişkenleri arasındaki ilişkiye göre çalışan tepe tırmanma değiştir ve gözlemle gibi isimlerle anılan yapıların kullanıldığı çalışmalar, REDS'lerde de kullanılabilmektedir [7- 9]. Parametrelerin belirli büyüklükteki değişimlerine göre anlık güç kontrolünü esas alan bu çalışmalarda kullanılan yöntemler matematiksel ve akış diyagramı şeklinde ifade edilerek maksimum güç kontrolü sağlanmış, modellemelerle sistem büyüklüklerinin analizi gerçekleştirilmiştir.

MGNI kontrolü için bahsedilen yaklaşımlar dışında bir diğer yaklaşım ise akıllı yapıları esas alan kontrol yöntemleridir. En önemli üstünlükleri kontrol edeceği sistemde kesin bir matematiksel model gerektirmeden esnek çalışma imkânı verebilmeleridir. Bu tür yöntemlerden bulanık mantık yöntemiyle REDS'de MGNİ kontrolünün yapıldığı çalışmalarda [10- 12] farklı bulanık mantık tasarımlarıyla kıyıcılı arayüz üzerinden kontrol sağlanmıştır.

$\mathrm{Bu}$ çalıșmada değişken hızlı rüzgâr türbiniyle uyumlu KMSG içeren REDS için sistemin ve kontrol yapılarının anlaşılabilmesi adına sisteme ait büyüklüklerin matematiksel modellerinden yararlanılmış, farklı türdeki MGNİ kontrol yöntemlerinin Matlab/Simulink ortamında modellenen REDS modeli üzerinden karşılaştırmalı analizleri gerçekleştirilmiştir. Kontrol yapılarının performansı çeşitli sistem büyüklüklerinin grafikleri üzerinden değerlendirilerek araştırmacılara uygun kontrol yöntemi seçimiyle ilgili bilgi sağlanması amaçlanmıştır.

\section{Materyal ve Yöntem}

Değişken hızlı KMSG içeren REDS için farklı alt bileşenlerden meydana gelen bir sistem söz konusudur. Kullanılan alt bileşenlere göre sistemdeki enerji dönüşümlerini gösteren şema Şekil 1'de görülmektedir

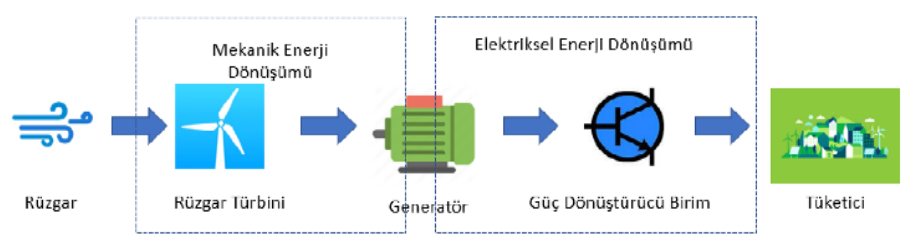

Şekil 1. REDS enerji dönüşüm şeması [13]

Şekil 1'e göre anlık rüzgârın kinetik enerjisi, türbin yapısıyla önce mekanik enerjiye ardından türbine bağlı olan generatör vasıtasıyla elektrik enerjisine dönüştürülmektedir. Elde edilen enerji istenirse şebekeye istenirse de şebekeden bağımsız lokal (tekil) çalışma moduyla da kullanılabilmektedir. Kullanılan sistem ve kontrol yöntemlerinin anlaşılabilmesi adına enerji dönüşümünde kilit öneme sahip büyüklüklerin matematiksel modellerinden yararlanılabilir.

\subsection{Türbin Modeli}

Anlık rüzgâr hızına göre türbin tarafından elde edilen mekanik güç, Denklem 1'deki gibi ifade edilir. 
$P_{\text {Mekanik }}=\frac{1}{2} \times p \times C_{P} \times A \times V_{R}^{3}$

Denklem 1'de $p$ hava yoğunluğu, $A$ türbin kanatlarının taradığı alan, $V_{R}$ rüzgâr hızını temsil etmektedir. $C_{P}$ ise REDS'lerde türbindeki mekanik enerjinin rüzgârın mevcut enerjisine oranı olarak da tanımlanabileceği gibi rüzgârdan ne kadar oranda faydalanılabildiğini gösteren güç (verimlilik) katsayısıdır [3, 13- 16]. Bu katsayı iki farklı değişkene göre Denklem 2'deki gibi ifade edilir.

$C_{P}(\lambda, \beta)=C_{1}\left(\frac{C_{2}}{\lambda_{i}}-C_{3} \times \beta-C_{4}\right) e^{-\left(C_{5} / \lambda_{i}\right)}+C_{6} \times \lambda, \frac{1}{\lambda_{i}}=\frac{1}{\lambda+0.08 \beta}-\frac{0.035}{\beta^{3}+1}$

$C_{1-6}$ ile ifade edilen parametreler, türbinlerin tasarımlarına göre belirlenen karakteristik değerlerdir. $\beta$ yüksek hızlarda türbinin zarar görmesini engelleyecek şekilde devreye girebilen kanat açısı, $\lambda$ ise kanat uç hız oranı (KHO) olarak tanımlanır. Bu oran matematiksel olarak Denklem 3'deki gibi ifade edilir.

$K H O(\lambda)=\frac{w_{M} \times R}{V_{R}}$

Burada R türbin kanat yarıçapı, $w_{M}$ türbinin ve ona doğrudan bağlı generatörün rotor açısal hızı, $\mathrm{V}_{\mathrm{R}}$ ise rüzgâr hızıdır. Güç katsayısı en uygun KHO ve kanat açısı değerlerinde maksimum 0.5926 değerini almaktadır. Bu maksimum değer aynı zamanda betz limiti olarak da adlandırılmaktadır [3]. Bu değer teorik olarak rüzgârın yaklaşık \%60'ından yararlanılabildiğini gösterir. Ancak pratikte kayıplardan dolayı anlık rüzgârdan maksimum $\% 40$ ile $\% 50$ arasında faydalanılırken güç katsayısı da en ideal 0.4 ile 0.5 arasında değerlerde tutulabilir [16- 17]. Güç katsayısı ve KHO arasındaki bağıntı türbindeki dönüşüm verimliliği adına en önemli kriterdir. Değişen kanat açısı değerlerine göre güç katsayısının KHO'ya göre değişimi Şekil 2'de görülmektedir.

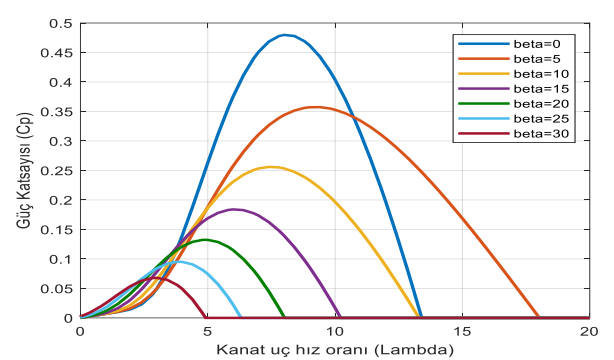

Şekil 2. Güç katsayısı KHO değişimi [3]

Şekil 2'ye göre güç katsayısı, kanat açısı değerinin en küçük değerde, KHO’nun uygun değerde tutulmasıyla maksimum değerini almaktadır. Denklem 3'e göre KHO, türbin kanat yarıçapı ve rotor açısal hızına bağlıdır. Denklemde kullanılan türbin kanat yarıçapı, sabit bir değer olduğundan değişen rüzgâr hızlarına göre rotor açısal hızını ayarlamak suretiyle KHO ve güç katsayısı en uygun değerlerde tutulabilir. Anlık rüzgâra göre çalışma hızını ayarlayarak güç katsayısını dolayısıyla sistem verimliliğini ayarlamak, MGNI kontrolünün temel prensibidir. Açısal hız ve rüzgâr hızı değişimlerine göre türbinden elde edilen mekanik gücün değişimi Şekil 3'te görülmektedir.

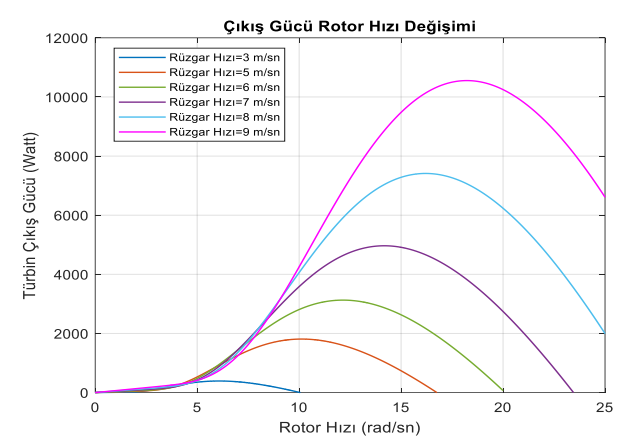

Şekil 3. Türbin çıkış gücünün rotor hızına göre değişimi 
Şekil 3 incelendiğinde çıkış gücü, belirli hızlarda maksimum değeri almaktadır. Kullanılacak kontrol yöntemiyle anlık rüzgâra göre generatörün çalışma hızı ayarlanarak güç maksimum seviyede tutulabilir.

\subsection{Generatör ve Arayüz Modeli}

Anlık rüzgâra göre MGNİ kontrolünde kullanılan kontrol yöntemlerinin uygulanmasında generatör ve yük arasında kullanılan güç dönüştürücü birimler (arayüzler) önemli rol oynamaktadır. Bu çalışmada genellikle kü̧̈ük ve orta güç seviyelerine uygun kıyıcılı arayüz kullanılmıştır. Doğrudan türbin bağlantılı KMSG içeren REDS'de generatör ve yük arasındaki arayüz için gerilim dönüşüm aşamaları Şekil 4'te görülmektedir.

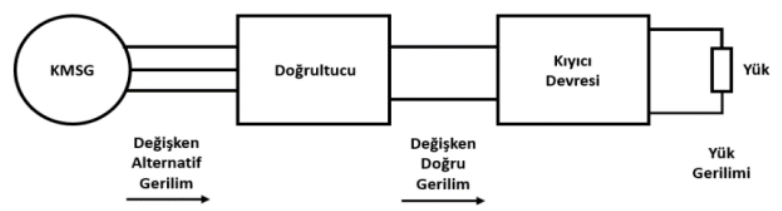

Şekil 4. KMSG arayüz dönüşüm yapısı

Şekil 4'e göre gerilim anlık değişimlerden etkilenmeden yüke aktarılmalıdır. Ancak anlık rüzgâra göre generatör çıkış gerilimi değişken yapıdadır. Bu gerilim bir doğrultucu aracılığıyla doğrultulsa da gerilim yapısında değişkenlik söz konusudur. Kıyıcı devresi, girişine uygulanan gerilime göre çıkışında istenen seviyede gerilim sağlayacak şekilde kullanılır. Gerilimdeki dönüşüm aşamalarına göre generatör ve doğrultucu arasındaki akım ve gerilim büyüklükleri arasındaki bağıntı Denklem 4 ve 5 'teki gibidir.

$V_{D}=\frac{3 \sqrt{6}}{\pi} V_{G E N}$

$I_{D}=\frac{\pi}{\sqrt{6}} I_{G E N}$

Denklemlerde $V_{G E N}$ ve $V_{D}$ srrasıyla generatörün faz geriliminin efektif değeri ve doğrultucu çıkış gerilimi; $I_{G E N}$ ve $I_{D}$ ise sırasıyla generatör akımı ve doğrultucu çıkışındaki akımı ifade etmektedir. Doğrultucu çıkışında bu çalışmada kullanılan yükselten (boost) tipi kıyıcı devresinin anlık kontrolüyle doğrultucudan gelen gerilime göre çıkışta daha yüksek seviyede bir gerilim elde edilebilir. Bu tip kıyıcıya ait devre şeması Şekil 5 ’teki gibidir.

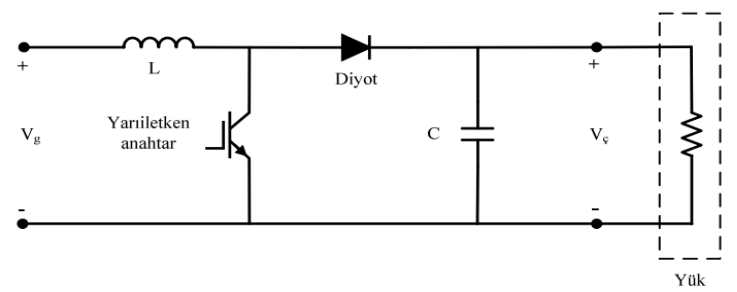

Şekil 5. Yükselten tip (boost) kıyıcı devre şeması

Kıyıcı devresindeki yariletken anahtarın iletim ve kesimde kalma sürelerine göre çıkışta daha yüksek seviyede bir gerilim elde edilebilir. Anahtarlama sürelerine göre kıyıcı devresi için Denklem 6 ve 7 elde edilir.

$T_{S}=t_{o n}+t_{o f f}$

$d=\frac{t_{\text {On }}}{T}$

Denklemlerde $T_{S}$ anahtarlama periyodunu, $t_{O n}$ ve $t_{O f f}$ srrasiyla anahtarın iletimde ve kesimde kalma süreleri, $d$ ise doluluk oranıdır. Doluluk oranı, 0 ile 1 arasında bir değerdir. Kıyıcı devresinin kontrolü esasında doluluk oranı kontrolüne dayanmaktadır. Kıyıcı giriş çıkış gerilimleri ve doluluk oranı arasındaki bağıntı Denklem 8'deki gibidir. 
$\frac{V_{\text {Çıkıs }}}{V_{\text {Giriș }}}=\frac{1}{1-d}$

Denklem 8'deki bağıntıya göre d'nin alabileceği değerler göz önüne alındığında çıkış gerilimi her zaman giriş gerilimine göre daha yüksek olacağından kıyıcı devresi yükselten tip olarak anılmaktadır. REDS'lerde kıyıcının doluluk oranı kontrolüyle çıkış geriliminin belirli bir seviyede tutulduğu düşünülürse doluluk oranı değiştikçe kıyıcıya doğrultucu tarafından gelen gerilim ayarlanabilir. Bu gerilimin genaratörün hızıyla orantılı olduğu düşünüldüğünde kıyıcı devresindeki anlık doluluk oranı kontrolü, anlık hız kontrolünü yani kıyıcı devreli arayüzde MGNİ kontrolünün temelini oluşturur [17].

Kontrol teknikleriyle kıyıcı devresinin kararlı şekilde çalışmasını sürdürebilmesi, kıyıcı devresinde kullanılan endüktans (L), kondansatör (C) elamanlarının ve anahtarlama frekansının uygun seçimlerine bağlıdır. Devrede kullanılabilecek L ve C değerleri için kritik değerler Denklem 9 ve 10'daki gibi hesaplanır [17- 18].

$\mathrm{L}=\frac{V_{g(\operatorname{Min})^{*} d}}{\Delta I_{L} f_{S}}$

$C=\frac{I_{c ̧}(\operatorname{Max})^{* d}}{\Delta V_{C} f_{S}}$

Denklemlerde $V_{g(\text { Min })}$ giriş geriliminin alabileceği minimum değer, $I_{c ̧ \text { (Max) }}$ çıkış akımının maksimum değeri, $f_{s}$ kıyıcı devresindeki anahtarlama frekansıdır. $\Delta I_{L}$ ve $\Delta V_{C}$ ise endüktans akımı ve kondansatör geriliminde ne kadarlık dalgalanmaya izin verilebileceğini gösteren yüzdesel değerlerdir. Uygun devre tasarımı hem kıyıcının çalışması hem de kullanılacak kontrol yönteminin kararlılığı açısından önemlidir.

\subsection{MGNI Kontrol Yöntemleri}

REDS'lerde üretim verimliliği sadece rüzgârın yoğunluğu ile değil aynı zamanda kullanılan kontrol yöntemleriyle anlık olarak üst seviyede tutulabilir. REDS'lerde kullanılabilen MGNİ yöntemleri birçok farklı kritere göre belirlenebilir. Sistem için uygun kontrol yönteminin belirlenmesinde en önemli kriter, maliyet performans dengesini gözeterek kontrol yöntemi seçimidir.

Uygulanma şekillerine göre dolaylı, doğrudan, akıllı yapılı yöntemler şeklinde MGNİ yöntemleri sınıflandırılabilir. Dolaylı yöntemler, sisteme ait mekanik büyüklükler üzerinden çalışırken doğrudan kontrol yöntemleri, elektriksel büyüklükler üzerinden çalışır. Akıllı yapılı yöntemler ise bulanık mantık, yapay sinir ağları, optimizasyon teknikleri vb. yapıların MGNİ kontrolü için kullanıldığı yöntemlerdir [19].

Dolaylı kontrol yöntemleri, uygulama kolaylığı açısından avantajlıdır. Bu türdeki yöntemlerden KHO yöntemi, KHO’yu elde ettiğimiz denklemi esas alarak anlık hız kontrolünü gerçekleştirebilmektedir. Yöntemin çalışma prensibi Şekil 6'da görülmektedir

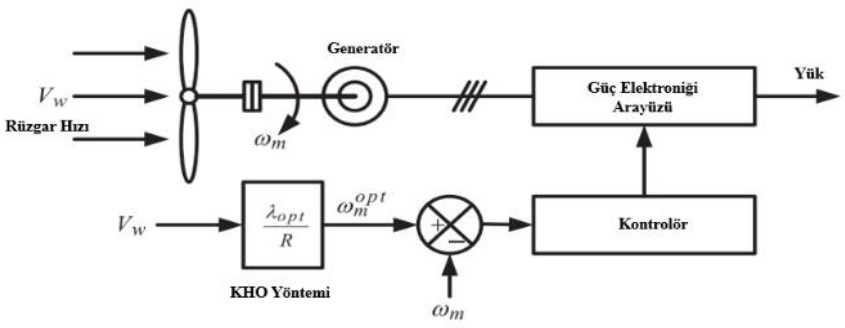

Şekil 6. KHO yöntemi çalışma şeması [19]

Şekil 6'da anlık rüzgâr hızına göre elde edilen referans hızın anlık açısal hızla karşılaştırılmasıyla anlık kontrol gerçekleştirilmektedir. Ancak bu yöntemin yüksek doğrulukta çalışan ek donanımlara ihtiyaç duyabilmesi, kullanım zamanı ve ortam koşullarına bağlı olarak değişen parametrelere bağımlılığı hem maliyet hem de performans açısından kontrol yöntemini olumsuz yönde etkiler [19- 20].

Kontrol değişkeni olarak REDS'lerde elektriksel büyüklüklerden yararlanan doğrudan yöntemler ise dolaylı yöntemler gibi yüksek maliyetli ek donanım gerektirmeden çalışabilirler. Bu tür yöntemlerden tepe tırmanma 
yöntemi, seçilen kontrol parametrelerinde yapılan belirli büyüklükteki değişimlerin, hedef parametrede meydana getirdiği değişimler üzerinden çalışmaktadır.

REDS'de bu yöntemin kullanımında kontrolü sağlanacak parametreler akım gerilim değerleri gibi elektriksel büyüklükler olabileceği gibi dolaylı olarak bu değerleri değiştirebilen kıyıcı doluluk oranı da alınabilir. Temel çalışma prensibi, seçilen parametrelere göre sistemin güç eğrisi üzerinde kontrol değişkenini ayarlayarak sistemin çalışma noktasını maksimum güç noktasında tutabilmektir [21]. Doluluk oranına göre gücün değişimi ve yöntemin çalışma şeması Şekil 7'de görülmektedir.

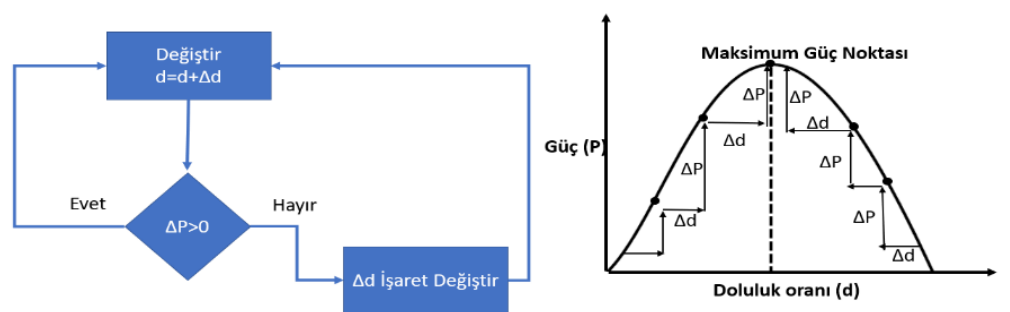

Şekil 7. Tepe tırmanma yöntemi şeması ve doluluk oranına göre gücün değişim eğrisi

Șekil 7'ye göre güçteki değişim $(\Delta \mathrm{P})$ 'nin işaretine göre doluluk oranında (d) yapılan değişikliklerle $(\Delta \mathrm{d})$, MGNİ kontrolü gerçekleştirilir. Eğrinin sol ya da sağ kısmına göre doluluk oranında artış ya da azalışla anlık maksimum gücün üretildiği çalışma noktasında sistemin çalışması sürdürülür. Basit yapısı ve doğrudan çalışması gibi avantajlara karşın bazı önemli dezavantajları da vardır. Belirli bir parametre için değişim büyüklüğünün seçimi, performans ve çalışma hızı açısından önemlidir. Değişim büyükse hızlı çalı̧̧mayla beraber büyük salınımlara sebep olurken, küçük değişimlerde salınım azalırken çalışma hızı düşer. Bu problemin aşılabilmesi adına değişim büyüklüğünün anlık çalışma noktasının konumuna göre adaptif yapıda olması yöntemin performansını iyileştirebilir [22]. Diğer bir dezavantajı ise rüzgâr hızında meydana gelen ani değişimleri kontrol yapısının güçte değişim olarak algılayıp çalışma noktasını maksimum güç noktasından uzaklaştıracak şekilde çalışabilmesidir.

Doğrudan ve dolaylı MGNİ yöntemlerinin dezavantajları, nonlineer yapıdaki REDS'lerde akıllı yapı tabanlı MGNİ yöntemlerinin kullanımına zemin hazırlamıştır [23]. Akıllı olarak tanımlanmaları, kullanıldıkları koşul ve sistemlere göre uyarlanabilir ve esnek performans göstermelerinden kaynaklanır. Bu tip yöntemlerden bulanık mantık yöntemi, insan mantığına göre ifade edilen sözel değişkenler ve bunlar arasında tanımlanan kurallar çerçevesinde çalışmaktadır. REDS'de bulanık mantık tabanlı MGNI kontrolü çalışma şeması Şekil 8'de görülmektedir.

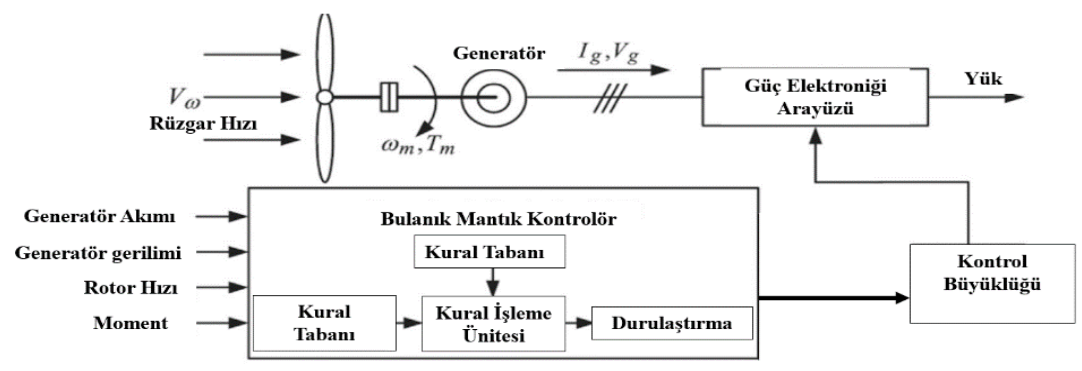

Şekil 8. Bulanık mantık tabanlı MGNİ kontrolü [19]

Şekil 8'de kontrol için farklı türde değişkenler kullanılabileceği gibi bu büyüklüklerin birbirlerine göre değişimleri de kullanılabilir. Kontrol performansını; tasarımı yapan kullanıcının sistem hakkında bilgisi, kullanılan değişkenlerin seçimi, kullanılan ara birimlerin uygun tasarımı ve kural tabanı belirler. REDS gibi hızlı değişimlere maruz kalan yapılar için kararlı, hızlı ve esnek çalışabilmeleri farklı kontrol amaçları için de bulanık mantık yapılarının sıklıkla kullanımını sağlamıştır [21, 23]. 


\section{Tartışma ve Bulgular}

Önceki bölümde açıklanan MGNİ kontrollerinin analizi için kıyıı arayüzü içeren REDS'nin Simulink modeli Tablo 1'de verilen parametreler üzerinden oluşturulmuştur.

Tablo 1. REDS modeli için kullanılan parametreler

\begin{tabular}{|l|c|l|c|}
\hline Türbin Parametreleri & & KMSG Parametreleri & \\
\hline Rotor Yarıçap1 & $4 \mathrm{~m}$ & Stator Direnci & $0.425 \Omega$ \\
\hline$p$ (Hava Yoğunluğu) & $1.2 \mathrm{~kg} / \mathrm{m}^{3}$ & Armatür Endüktans1 & $0.000835 \mathrm{H}$ \\
\hline Kanat Açısı & $0^{\circ}$ & Ak1 Bağı & $0.433 \mathrm{~Wb}$ \\
\hline Optimal KHO & 8.4 & Atalet (J) & $0.01197 \mathrm{~kg} \cdot \mathrm{m}^{2}$ \\
\hline Optimal Güç katsayıs1 & 0.48 & Sürtünme (Viskoz) Katsayı1s1 (B) & $0.001189 \mathrm{Nms}$ \\
\hline Yük & $50 \Omega$ & Kutup Çifti & 4 \\
\hline
\end{tabular}

Seçilen türbin ve generatör parametrelerine göre REDS'nin simulink modeli Şekil 9'da görülmektedir.

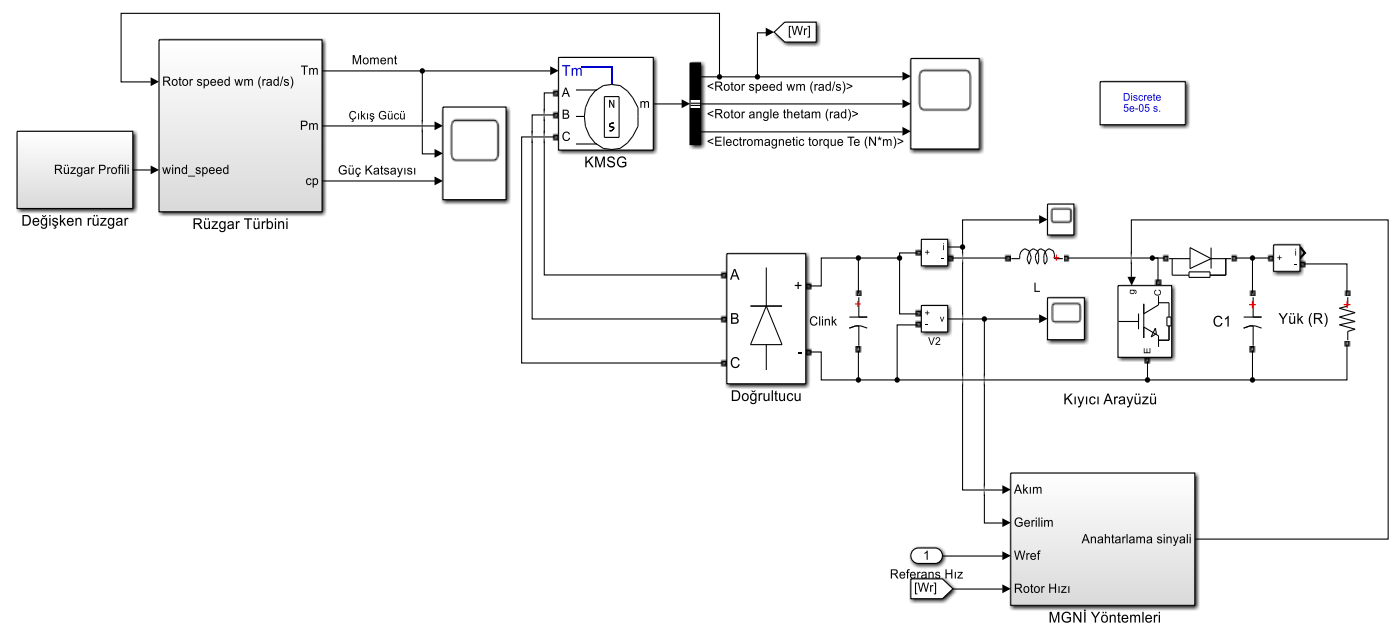

Şekil 9. REDS genel simulink modeli

Anlık rüzgâr profiline göre türbinden üretilen moment ve güç, Tablo 1'deki parametreler ve türbin modelindeki matematiksel ifadeler üzerinden elde edilir. Üretilen momentin KMSG’ye uygulanmasıyla generatör tarafindan üretilen gerilim doğrultucu ve kıyıcı arayüzü üzerinden yüke aktarılır. Şekil 9'daki MGNİ yöntemleri bloğu, üç tekniğe göre oluşturulmuş girişindeki hız değerleri KHO yöntemi, elektriksel büyüklükler ise hem tepe tırmanma hem de bulanık mantık yöntemi için kullanılmıștır. Kullanılan MGNİ yöntemleri için üretilen doluluk oranı, anahtarlama sinyali aracılığıyla kıyıcıdaki anahtara uygulanmıştır Kullanılan kıyıcı devresi için parametreler ise Tablo 2'de görülmektedir.

Tablo 2. Kıyıcı arayüzü parametreler

\begin{tabular}{|c|c|}
\hline Parametreler & Değerler \\
\hline Endüktans $(\mathrm{L})$ & $3 \mathrm{mH}$ \\
\hline Kapasite $\left(\mathrm{C}_{\text {link }}, \mathrm{C}_{1}\right)$ & $2 \times 10^{-5} \mathrm{~F}$ \\
\hline Anahtarlama Frekans1 (fs) & $10 \mathrm{kHz}$ \\
\hline Anahtar Tipi & IGBT \\
\hline
\end{tabular}


MGNİ kontrol yöntemlerinden bulanık mantık yapılı kontrole ait üyelik fonksiyonları ve kural tabanı Şekil 10 'da görülmektedir.

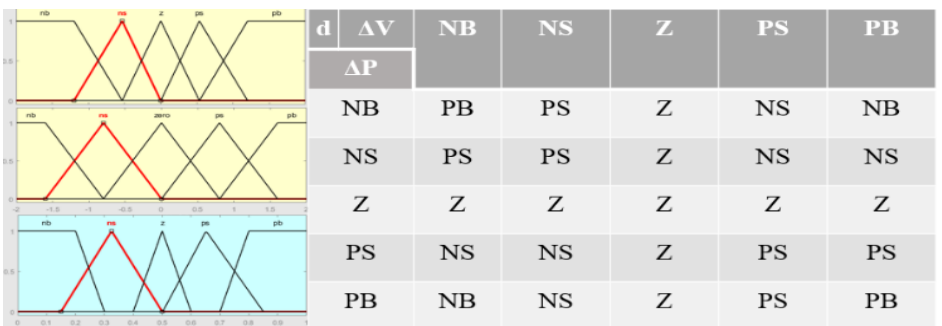

Şekil 10. Bulanık mantık tabanlı MGNİ yöntemi için üyelik fonksiyonları ve kural tabanı

Giriş değişkenleri olarak kıyıcı girişindeki akım ve gerilimlere göre elde edilen gücün değişimi $(\Delta \mathrm{P})$ ve generatör geriliminin değişimi $(\Delta \mathrm{V})$ seçilmiş. Bunlara göre değişimin yönü ve büyüklüğüne göre negatif büyük (NB), negatif küçük (NS), sıfır (Z), pozitif küçük (PS), pozitif büyük (PB) şeklinde üyelik fonksiyonları oluşturularak değişkenlerdeki değişime göre doluluk oranını artıracak ya da azaltacak şekilde çalışma amaçlanmıştır. Tepe tırmanma yöntemine göre en önemli farkı tepe tırmanmada bu değişim belirli büyüklükte yapılırken bulanık mantıkta kural tabanı aracılığıyla doluluk oranındaki değişim daha esnek yapıdadır.

Kullanılan yöntemlerin performansını değerlendirebilme adına Şekil 11'deki gibi değişken rüzgâr profilinden yararlanılmıştır.

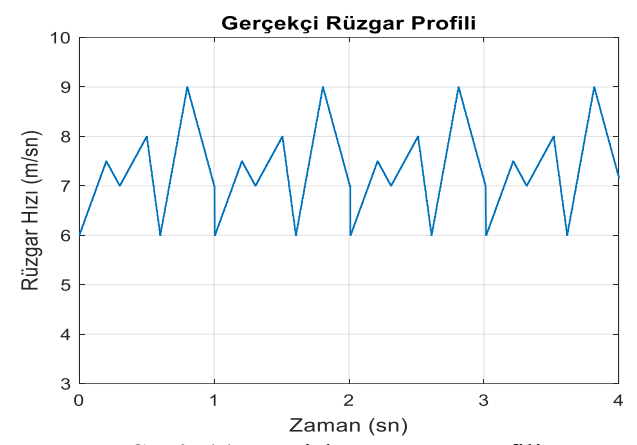

Şekil 11. Değişken rüzgâr profili

Şekil 11'deki 6 ile $9 \mathrm{~m} / \mathrm{sn}$ aralığındaki değişimlere göre sistemin MGNİ kontrolüyle güç katsayısının maksimum değerini elde edebilmek için kanat açısı değeri $0^{\circ}$, KHO’nun değeri 8.4, güç katsayısının buna karşılık 0.48 olduğu belirlenmiştir. Alınan bu referans değerlere göre kullanılan üç yöntem için KHO ve güç katsayısı değişimleri Şekil 12'de görülmektedir.
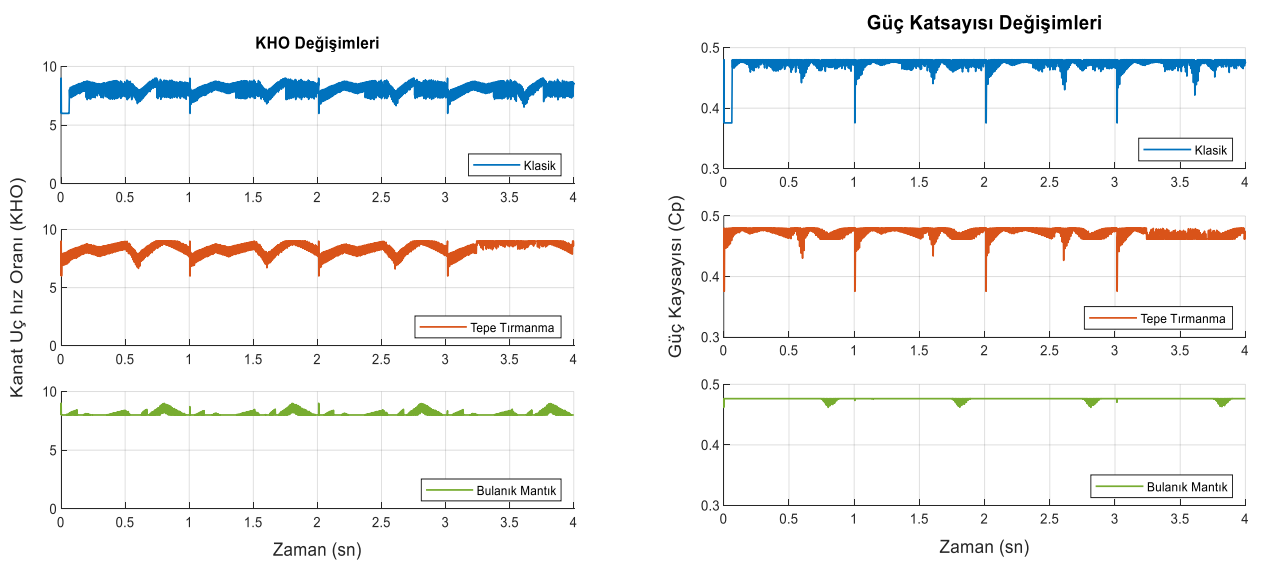

Şekil 12. Üç farklı tekniğe göre KHO ve güç katsayısı değişimleri 
Şekil 12'deki grafikler incelendiğinde bulanık mantık tabanlı yöntem, diğer iki yönteme göre daha kararlı ve referans değerlere yakın değişimler gözlemlenmiştir. Değişimler bulanık mantık yapısının daha kararlı ve daha verimli çalışma gerçekleştirdiğini göstermiştir.

Kullanılan yöntemlerde temel hedef, anlık çalışma hızının referans hıza göre ayarlanmasıdır. Değişen rüzgâr hızlarına göre kullanılan yöntemler için çalışma hızlarının referans hıza göre değişimi Şekil 13’teki gibidir.
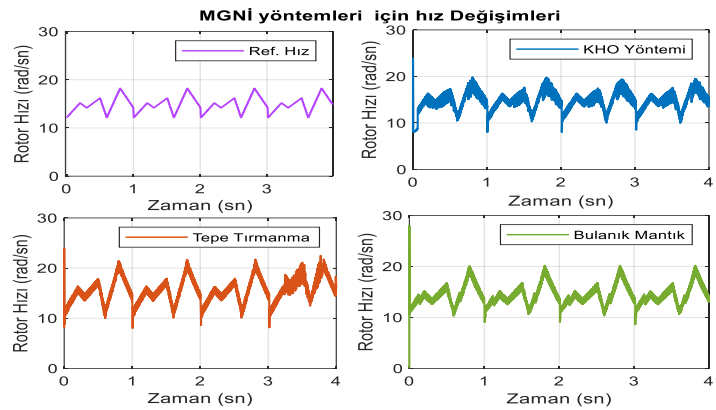

Şekil 13. MGNİ yöntemleri için anlık generatör hızının referans hıza göre değişimi

Referans hız değeriyle diğer kontrol yöntemlerinin sağladığı hız değişimleri karşılaş̧ırıldığında bulanık mantıklı tabanlı yöntemde daha kararlı ve referans hız değerine yakın değişimler gözlemlenmiş̧ir. Kullanılan MGNI yöntemleri için anlık rüzgâra göre türbinden elde edilen güç değiş̧imleri ise Şekil 14'te görülmektedir.

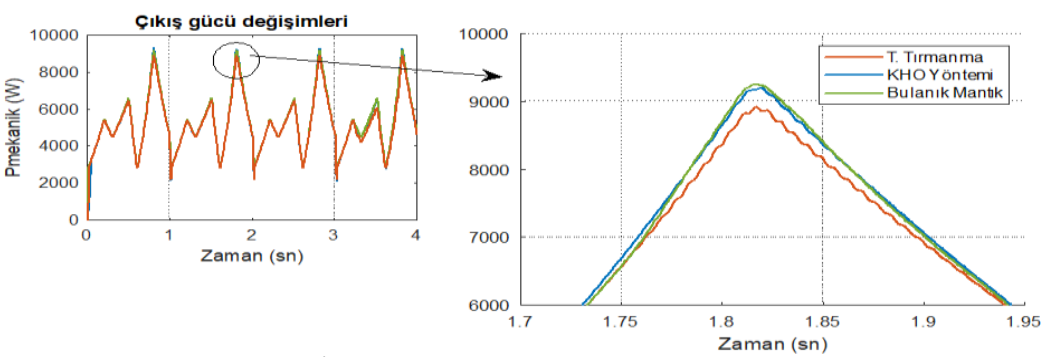

Şekil 14. MGNİ kontrollerine göre türbin çıkış gücü değişimleri

Çıkıș gücü değișimlerinde kullanılan kontrol yöntemlerinin tümünde rüzgâr profiliyle uyumlu değișimler gözlemlenmiştir. Tepe tırmanma yöntemi diğer iki yönteme göre düşük değerlerde değişim gösterirken bulanık mantık tabanlı yöntem ise diğer yapılara göre yüksek değerlerde değişim gösterdiği görülmektedir. Seçilen yöntemlere göre elde edilen ortalama güç değerleri Tablo 3’te görülmektedir.

Tablo 3. Kullanılan MGNİ yöntemlerine göre ortalama çıkış gücü değişimleri

\begin{tabular}{|c|c|}
\hline Kontrol Yöntemi & Ortalama Güç Değeri (W) \\
\hline Klasik Yöntem & 5930 \\
\hline Tepe Tırmanma & 5742 \\
\hline Bulanık Mantık & 6189 \\
\hline
\end{tabular}

Tablo 3'e göre Bulanık mantıklı tabanlı MGNİ kontrolüyle diğer iki yönteme göre daha yüksek güç değeri elde edilmesi bu yöntemin verimlilik adına diğer iki yönteme göre daha iyi performans verdiğini göstermiștir.

\section{Sonuçlar}

Bu çalıșmada değişken hızlı çalışmaya uygun, KMSG ve kıyıcı arayüzüne sahip REDS için anlık verimliliği en yüksek seviyede tutma amacıyla kullanılan MGNI yönteminin temel çalışma prensibi açıklanmış. MGNI kontrolü yöntemlerinden KHO, tepe tırmanma ve bulanık mantık tabanlı kontrollerin Matlab/Simulink ortamında karşılaş̧ırmalı analizi gerçekleştirilmiştir. Yapılan analizlerde bulanık mantık tabanlı yöntemin diğer iki yönteme göre daha kararlı, daha verimli çalıșmayı sağladığı belirlenmiştir. Bu da akıllı yapı olarak tanımlanan bulanık mantığın MGNİ kontrolünde uygunluğunu ortaya koymuştur. 
Bu çalışmada kullanılan bulanık mantık dışında yapay sinir ağları, farklı optimizasyon teknikleri gibi akıllı yapılar, REDS için farklı kontrol amaçları için kullanılabilir. REDS'lerde MGNi çalışmalarında birden fazla kontrol yönteminin birlikte kullanımını esas alan hibrid yapıların da bu çalışmadaki benzer modelleme mantığıyla analizi gerçekleştirilebilir.

\section{Kaynaklar}

[1] Rolan, A., Luna, A., Vazquez, G., Aguilar, D., Azevedo, G. Modeling of a variable speed wind turbine with a permanent magnet synchronous generator. In 2009 IEEE international symposium on industrial electronics; 0508 June 2009; South Korea, pp. 734-739.

[2] Yin, M., Li, G., Zhou, M., \& Zhao, C. Modeling of the wind turbine with a permanent magnet synchronous generator for integration. In 2007 IEEE Power Engineering Society General Meeting; June 2007, pp. 1-6.

[3] Ackermann T. Wind Power in Power Systems, United Kingdom, John Wiley \& Sons, Ltd, 2005.

[4] Sharma, H. K., Samaria, A., \& Gidwani, L. Designing and performance analysis of controller for PMSG based wind energy conversion system. In 2017 International Conference on Information, Communication, Instrumentation, and Control (ICICIC); 17-19 August 2017; Indore, India, pp. 1-6.

[5] Abbaker, O. Control of wind turbine for variable speed based on fuzzy-PID controller. Journal of Engineering and Computer Science (JECS) 2017; 18(1): 40-51

[6] Vijayalakshmi, G., \& Arutchelvi, M. Design and development of controller for PMSG based Wind Energy Conversion system. In 2014 International Conference on Circuits, Power and Computing Technologies;2014; pp. 573-578.

[7] Kumari, S., Kushwaha, V., \& Gupta, T. N. A Maximum Power Point Tracking For a PMSG Based Variable Speed Wind Energy Conversion System. In 2018 International Conference on Power Energy, Environment and Intelligent Control (PEEIC); 2018; pp. 789-794.

[8] Zammit, D., Staines, C. S., Micallef, A., Apap, M. Optimal power control for a PMSG small wind turbine in a gridconnected DC microgrid. In 2018 5th International Conference on Control, Decision and Information Technologies (CoDIT); 2018; pp. 32-37.

[9] Sahin, P., Resmi, R., Vanitha, V. PMSG based standalone wind electric conversion system with MPPT. In 2016 International Conference on Emerging Technological Trends (ICETT);2016; pp. 1-5.

[10] Prajapati, K. R. Application of fuzzy logic for MPPT control in stand-alone wind energy conversion system with a battery storage system. In 2019 IEEE International Conference on Intelligent Techniques in Control, Optimization and Signal Processing (INCOS); 2019; pp. 1-6.

[11] Tiwari, R., \& Babu, N. R. Fuzzy logic based MPPT for permanent magnet synchronous generator in wind energy conversion system. IFAC-PapersOnLine, 2019; 49(1): 462-467.

[12] Ngo, Q. V., Yi, C., Nguyen, T. The maximum power point tracking based-control system for small-scale wind turbine using fuzzy logic. International Journal of Electrical and Computer Engineering (IJECE) 2020; pp. 3927-3935.

[13] Percin H.B., Caliskan A. (2020). Modelıng And Analysis Of Pitch Angle Control On Variable Speed Wind Turbines, In 2020 International Engineering and Natural Sciences Conference (IENSC), 5-6 November 2020, Diyarbakır, Turkey, pp. 131-140.

[14] Gajewski, P., Pieńkowski, K. Advanced Control of Direct-Driven Pmsg Generator in Wind Turbine System. Archives of Electrical Engineering, 2016; 65(4): 643-656.

[15] Wu, B., Lang, Y., Zargari, N., \& Kouro, S. Power conversion and control of wind energy systems, New York, NY, USA John Wiley \& Sons, 2011.

[16] Bianchi, F. D., De Battista, H., Mantz, R. J. Wind turbine control systems: principles, modelling and gain scheduling design. Springer Science \& Business Media, 2006.

[17] Soetedjo, A., Lomi, A., \& Mulayanto, W. P. Modeling of wind energy system with MPPT control. In Proceedings of the 2011 International Conference on Electrical Engineering and Informatics; July 2011; pp. 1-6.

[18] Koutroulis, E., \& Kalaitzakis, K. Design of a maximum power tracking system for wind-energy-conversion applications. IEEE transactions on industrial electronics, 2006, 53(2): 486-494.

[19] Abdullah, M. A., Yatim, A. H. M., Tan, C. W., \& Saidur, R. A review of maximum power point tracking algorithms for wind energy systems. Renewable and sustainable energy reviews, 2012; 16(5): 3220-3227.

[20] Jha, D. A comprehensive review on wind energy systems for electric power generation: current situation and improved technologies to realize future development. International Journal of Renewable Energy Research (IJRER) 2017; 7(4): 1786-1805.

[21] Govinda, C. V., Udhay, S. V., Rani, C., Wang, Y., \& Busawon, K. A review on various MPPT techniques for wind energy conversion system. In 2018 International conference on computation of power, energy, Information and Communication (ICCPEIC); 2018; pp. 310-326.

[22] Yüksek, G., \& Mete, A. N. A hybrid variable step size MPPT method based on P\&O and INC methods. In 2017 10th International Conference on Electrical and Electronics Engineering (ELECO); 2017. pp. 949-953.

[23] Thongam, J. S., \& Ouhrouche, M. MPPT control methods in wind energy conversion systems. Fundamental and advanced topics in wind power, 2011, (1): 339-360. 